\title{
Opioid modulation of Fos protein expression and olfactory circuitry plays a pivotal role in what neonates remember
}

\author{
Tania L. Roth, ${ }^{1}$ Stephanie Moriceau, and Regina M. Sullivan \\ Department of Zoology, University of Oklahoma, Norman, Oklahoma 73019, USA
}

\begin{abstract}
Paradoxically, fear conditioning (odor- $0.5 \mathrm{~mA}$ shock) yields a learned odor preference in the neonate, presumably due to a unique learning and memory circuit that does not include apparent amygdala participation. Post-training opioid antagonism with naltrexone (NTX) blocks consolidation of this odor preference and instead yields memory of a learned odor aversion. Here we characterize the neural circuitry underlying this switch during memory consolidation. Experiment 1 assessed post-training opioid modulation of Fos protein expression within olfactory circuitry (olfactory bulb, piriform cortex, amygdala). Odor-shock conditioning with no post-training treatment (odor preference) induced significant changes in Fos protein expression in the granule cell layer of the olfactory bulb and anterior piriform cortex. Post-training opioid receptor antagonism (odor aversion) prevented the learning-induced changes in the anterior piriform cortex and also induced significant changes in Fos protein expression in the central nucleus of the amygdala. Experiment 2 assessed intra-amygdala opioid modulation of neonate memory consolidation. Post-training infusion of NTX within the amygdala permitted consolidation of an odor aversion, while vehicle-infused pups continued to demonstrate an odor preference. Overall, results demonstrate that opioids modulate memory consolidation in the neonate via modulating Fos protein expression in olfactory circuitry. Furthermore, these results suggest that opioids are instrumental in suppressing neonate fear behavior via modulating the amygdala.
\end{abstract}

Odor-shock conditioning, a learning paradigm that readily produces fear in adult animals, produces a paradoxical odor preference in rat pups $<10 \mathrm{~d}$ old (Camp and Rudy 1988; Sullivan et al. 2000a; Roth and Sullivan 2001, 2003, 2005; Moriceau and Sullivan 2004a). This paradoxical behavior is attributable to a relatively simplistic olfactory learning and memory circuit that incorporates the olfactory bulb, anterior piriform cortex, and an apparent lack of amygdala participation (Sullivan et al. 2000a,b; Moriceau and Sullivan 2004a,b; Roth and Sullivan 2005; Moriceau et al. 2006). Indeed, we have demonstrated that the emergence of learned fear coincides with significant amygdala participation (Sullivan et al. 2000a; Moriceau et al. 2006). We suggest this attenuated aversion learning and potentiated preference learning early in development ensures pups readily learn to approach the maternal odor regardless of the quality of care she provides. Indeed, a recent study from our laboratory has documented this paradoxical odor preference learning within a seminatural nest environment as an odor paired with rough handling from a stressed mother resulted in a preference for that odor (Roth and Sullivan 2005). A similar paradoxical attachment despite caregiver abuse has been demonstrated in other species: chick (Hess 1962), infant dogs (Rajecki et al. 1978), and nonhuman primates (Harlow and Harlow 1965; Maestripieri et al. 1997, 1999).

We have previously demonstrated a pivotal role of opioids in facilitating neonate (PN7-8) learning and memory (Roth and Sullivan 2001, 2003). Specifically, an opioid receptor antagonist delivered before odor-shock conditioning disrupts acquisition of an odor preference, while in sharp contrast an opioid receptor antagonist administered immediately following the condition-

\footnotetext{
'Corresponding author.
}

E-mail troth@nrc.uab.edu; fax (205) 934-6571.

Article is online at http://www.learnmem.org/cgi/doi/10.1101//m.301206. ing, disrupts memory consolidation of an odor preference and yields an odor aversion. Antagonism of the opioid system has also been shown to enhance fear learning and memory in adults, although fear conditioning in adults readily evokes learned fear (Fanselow 1984; McGaugh et al. 1988; Fanselow et al. 1991; McNally et al. 2004). The site of opioids' ability to dramatically alter neonate learned behavior, that is, to thwart learned fear, remains unclear.

Here we will explore the neural basis of the opioiddependent switch from odor preference to odor aversion during memory consolidation following odor-shock conditioning. Specifically, in Experiment 1 we assessed opioid modulation of neonate fear circuitry, with emphasis on the path of olfactory information to the amygdala, which includes the olfactory bulb with a direct connection to the amygdala and an indirect connection between these two brain areas via the piriform cortex. In Experiment 2, we assessed opioid modulation of memory consolidation within the amygdala.

\section{Results}

Experiment 1: Opioid antagonism post-training switches memory consolidation and alters Fos protein expression We have previously demonstrated that a learned odor preference in neonates results in significant Fos protein expression, a synaptic plasticity gene product contributing to memory (Herrera and Robertson 1996; Dragunow and Bilkey 2002; Kaczmarek 2002), within the olfactory bulb and piriform cortex (Roth and Sullivan 2005). We have also demonstrated that systemic opioid receptor antagonism immediately following odor-shock conditioning disrupts consolidation of the neonate odor preference and instead yields consolidation of an odor aversion (Roth and Sullivan 2001, 2003). Our goal with Experiment 1 was to assess the effect of post-training opioid receptor antagonism on Fos 
protein expression within olfactory learning and memory circuitry (amygdala, and the two major pathways of olfactory input to the amygdala: the olfactory bulb and piriform cortex). We hypothesized that post-training opioid receptor antagonism would alter the pattern of Fos protein expression within the olfactory learning and memory circuitry.

For pups that were tested the day following odor-shock conditioning, ANOVA analysis revealed a significant training condition $\times$ drug interaction, $F_{(1,26)}=17.09, P<0.01$ (Fig. 1). Post hoc comparisons showed that the saline-treated paired conditioned pups chose peppermint during the Y-maze test significantly more times than did all other subjects $(P<0.05)$. Subjects given paired odor-shock presentations followed by NTX chose the odor significantly less times than did all other subjects $(P<0.05)$. No drug effect was seen within the control condition.

For pups that were used for immunohistochemistry $90 \mathrm{~min}$ following odor-shock conditioning (and thus were not tested the following day in a Y-maze), we assessed behavior during the training process. Analysis of acquisition curves of these pups indicated that any differences seen in Fos protein expression were not attributable to differences in acquisition of the odor-shock association during training. Acquisition curves indicated that all subjects had similar preconditioning behavior during the $10 \mathrm{sec}$ prior to the odor presentations (Fig. 2A), while analysis of activity in response to the odor presentations indicated a significant training condition $\times$ training trial interaction, $\left(F_{(6,132)}=25.992\right.$, $P<0.01$ ) (Fig. 2B). Post hoc tests showed that subjects receiving paired presentations of odor and shock demonstrated significant conditioned behavioral activation (indicative of learning in motorically immature animals) to the odor in comparison to control subjects $(P<0.05)$, and there was no difference in subjects within the paired odor-shock condition prior to the post-training drug treatment.

Ninety minutes following aversive conditioning, experience-induced changes were observed in the number of Fospositive cells in the granule cell layer of the olfactory bulb (training condition effect, $F_{(1,16)}=12.320, P<0.01$ ) (Fig. 3). Analysis with post hoc Fisher tests revealed that the paired presentations of odor-shock, including both saline- and NTX-treated pups, induced significantly less Fos in the granule cell layer in comparison to control presentations $(P<0.05)$. Woo et al. (1996) simi-

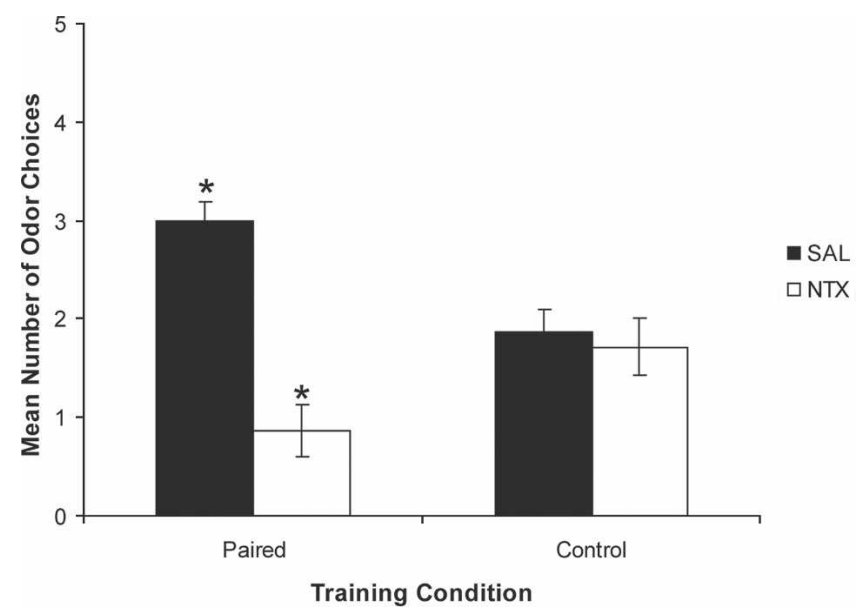

Figure 1. Antagonism of opioid receptors following odor-shock conditioning in neonates yields consolidation of an odor aversion instead of the age-typical preference. Bars represent the number of choices (mean \pm SEM) toward peppermint during Y-maze testing for pups that received paired presentations of odor and shock (SAL, $n=8 ;$ NTX, $n=7$ ) or control presentations (SAL, $n=8 ; \mathrm{NTX}, n=7$ ). SAL indicates saline; NTX, naltrexone. ${ }^{*} P<0.05$.
A)

Before odor presentation

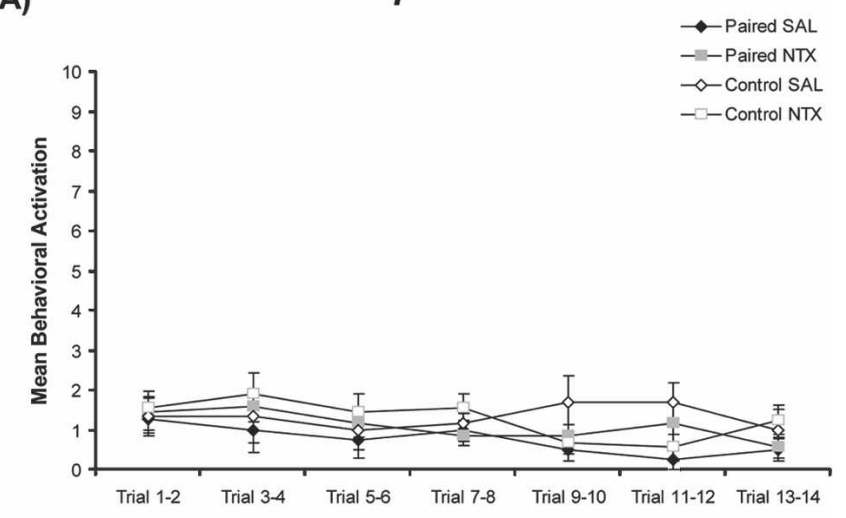

B)

During odor presentation

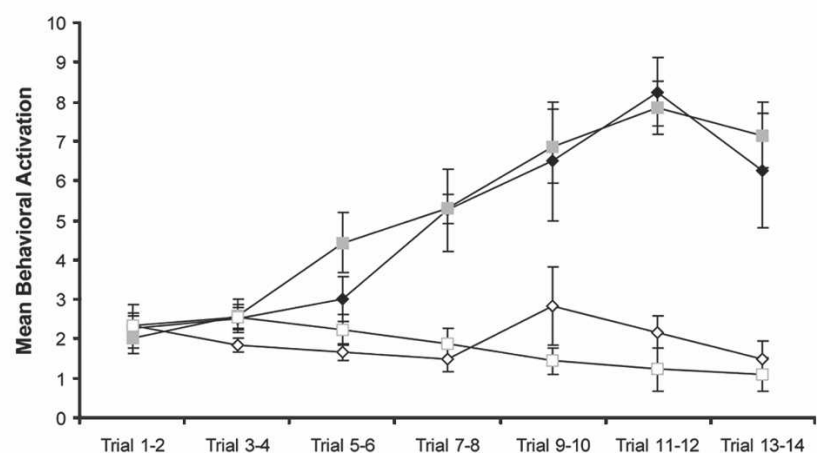

Figure 2. Behavioral activation scores indicate that pups used for immunohistochemical neural analysis had significant acquisition, indicative of learning, and that any changes in Fos expression were not reflecting differences in behavior during odor-shock conditioning. (A) Pup activity before odor presentations during conditioning with either paired odorshock presentations (post-training SAL, $n=4 ; \mathrm{NTX}, \mathrm{n}=7$ ) or control presentations (post-training $\mathrm{SAL}, \mathrm{n}=6$; $N T X, \mathrm{n}=9$ ). Each data point represents the summation of behavior from two consecutive trials; mean \pm SEM. There was no effect of conditioning treatment on pup activity before odor presentations. (B) Pup activity during odor presentations indicates that only paired presentations of odor-shock resulted in learning. SAL indicates saline; NTX, naltrexone.

larly documented a decrease in Fos expression within the granule cells of the olfactory bulb in young rats with a learned odor preference. Figure 4A provides representative images of Fos staining within the olfactory bulb.

ANOVA analysis revealed a significant training condition $x$ drug interaction effect on Fos expression in the anterior piriform cortex $\left(F_{(1,19)}=5.286, P<0.04\right)$ (Fig. 3), and a training condition effect in the posterior piriform cortex $\left(F_{(1,16)}=9.223, P<0.01\right)$ (Fig. 3). Post hoc Fisher tests showed that paired presentations of odor-shock evoked significantly more Fos expression in the anterior piriform cortex than all other subjects $(P<0.05)$. NTX posttraining prevented this increase in the anterior piriform cortex within the paired odor-shock condition, but produced no significant effect within the posterior piriform cortex.

No effects of training condition or drug treatment were observed within the basolateral/lateral amygdala. However, a significant training condition $\times$ drug interaction was observed in the central nucleus of the amygdala $\left(F_{(1,16)}=6.761, P<0.02\right)$ (Fig. 3). In pups that demonstrated a behavioral odor preference (saline-treated paired odor-shock subjects), and in the controls, there was no significant activity. However, in pups that demonstrated an odor aversion (NTX-treated paired odor-shock sub- 


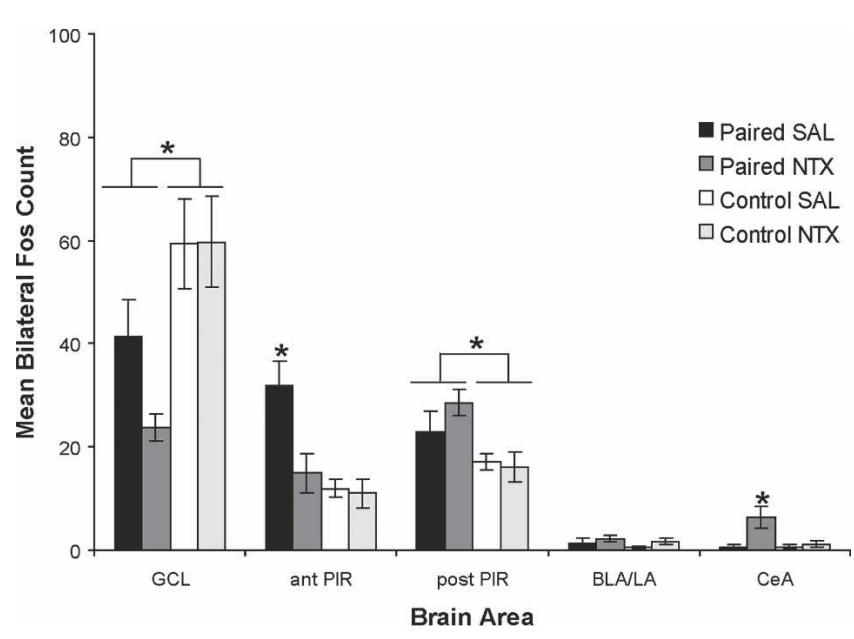

Figure 3. Post-training antagonism of opioid receptors alters the pattern of learning-induced Fos protein expression. Opioid receptor antagonism prevented the increase of Fos expression in the anterior piriform cortex and produced a significant increase of Fos expression in the central nucleus of the amygdala. Bars represent the number (mean \pm SEM) of Fos-positive cells counted bilaterally in each brain area for subjects receiving paired presentations of odor-shock (SAL, $n=4 ; N T X, n=4-6$ ), or control presentations (SAL, $n=5-6 ; N T X, n=6-7)$. SAL indicates saline; NTX, naltrexone; GCL, granule cell layer of olfactory bulb; ant or post PIR, anterior or posterior piriform cortex; and BLA/LA or CeA, basolateral/ lateral or central nucleus of the amygdaloid complex. ${ }^{*} P<0.05$.

jects) a significant increase in Fos expression was observed in the central amygdala $(P<0.05)$. Figure 4B provides representative images of Fos staining within the central amygdala.

\section{Experiment 2: Disruption of opioids} within the amygdala permits consolidation of an odor aversion

Here we assessed the role of post-training opioids within the infant amygdala following odor-shock conditioning. Previous research has shown that a shock-induced odor preference in the neonate is attributable to an apparent lack of amygdala participation (Sullivan et al. 2000a; Roth and Sullivan 2005), and that the emergence of a learned odor aversion later in development is associated with significant amygdala participation (Sullivan et al. 2000a). In addition, post-training manipulation of the opioid system in neonates has been shown to disrupt consolidation of the shock-induced odor preference and yield an odor aversion. Since the amygdala displays one of the highest densities of opioid receptor binding sites (Atweh and Kuhar 1977; Mansour et al. 1987; Unterwald et al. 1998), this suggests it may have a critical role in the dramatic shift from the preference to avoidance memory when neonatal pups' opioid system is disrupted during consolidation. Furthermore, in the adult, post-training intraamygdala infusion of NTX facilitates consolidation of emotional experiences (McGaugh et al. 1988; Quirate et al. 1998). Thus, we hypothesized in Experiment 2 that post-training intra-amygdala opioid receptor antagonism would be sufficient to disrupt consolidation of the neonate odor preference and yield an odor aversion.

ANOVA analysis revealed a significant training condition $\times$ drug interaction, $F_{(2,26)}=6.52, P<0.01$ (Fig. 5). Post hoc comparisons showed that the saline-treated paired conditioned pups chose peppermint during the Y-maze test significantly more times than did all other subjects $(P<0.05)$. Subjects given paired odor-shock presentations followed by infusion of $1.0 \mu \mathrm{g}$ NTX chose the odor significantly less times than did all other subjects, with the exception of the paired odor-shock subjects with $0.1 \mu \mathrm{g}$ NTX. No drug effect was observed in the control condition. His- tological analysis indicated that all cannulas were implanted into the amygdaloidal complex, and composite reconstructions of cannula tip placement are provided in Figure 6A. Figure 6B demonstrates that the volume of drug infused diffused $<1 \mathrm{~mm}$ from the amygdaloidal complex.

\section{Discussion}

Fear conditioning in adult animals has been instrumental to our understanding of the neurobiology contributing to the learning and memory of adaptive behaviors. For example, critical components of adult fear conditioning circuitry include the thalamus, hippocampus, frontal cortex, and amygdala, with the basolateral complex of the amygdala serving as a potential site for stimuli associations (LeDoux et al. 1990; Fendt and Fanselow 1999; Schafe et al. 2000; Maren 2001; Davis et al. 2003; Fanselow and Poulos 2005; Rudy and Matus-Amat 2005). A myriad of neurotransmitters modulate learned fear within the amygdala (Lalumiere et al. 2004; McGaugh 2004; Pezze and Feldon 2004), and one such modulator is the endogenous opioid system (McGaugh et al. 1988; Good and Westbrook 1995). Here we assess the role of the opioid system in the infant's fear circuitry during memory consolidation.

\section{Opioids modulate learned odor behavior in neonates}

Behavioral studies demonstrate a functional opioid system supporting learning and memory early in development. For example, odor paired with morphine or sucrose is sufficient to produce a conditioned odor preference in rat neonates, which is blocked with NTX (Kehoe and Blass 1986; Shide and Blass 1991; Barr and Rossi 1992; Randall et al. 1992). Indicative of the role of opioids in the rewarding aspects of mother-infant interactions, opioid receptor antagonism prevents the learning of an odor preference for an odor paired directly with maternal care in older pups (Panksepp et al. 1994). Furthermore, mice lacking $\mu$-opioid receptors do not demonstrate a preference toward maternal odor (Moles et al. 2004).

To assess neurocircuitry mediating neonatal learning and memory, we use odor- $0.5 \mathrm{~mA}$ shock conditioning. This is an adult fear-conditioning paradigm that paradoxically produces conditioned odor preferences in rat neonates $<10 \mathrm{~d}$ old (Camp and Rudy 1988; Sullivan et al. 2000a; Roth and Sullivan 2001, 2003). We have previously shown that opioids are necessary for the acquisition, consolidation, and expression of the shockinduced odor preference (Roth and Sullivan 2001, 2003). Specifically, opioid receptor antagonism prior to odor-shock conditioning or behavioral testing in neonates disrupts odor preference acquisition or expression, respectively. In sharp contrast, opioid receptor antagonism post-training not only disrupts memory consolidation of an odor preference but also permits an odor aversion. Overall, behavioral studies underscore opioid facilitation of neonate learning and memory.

\section{Opioids modulate neurocircuitry supporting neonate memory}

We have recently documented changes in Fos expression in neonate olfactory learning and memory circuitry (olfactory bulb, anterior piriform cortex) presumably responsible for the consolidation of conditioned odor preferences (Roth and Sullivan 2005). We now corroborate these findings and show that opioids modulate this circuitry. In neonates that demonstrate a conditioned odor preference (post-training treatment with saline), there is (1) a significant decrease in Fos protein expression in the granule cell layer of the olfactory bulb; (2) a significant increase in Fos protein expression in the anterior piriform cortex; and (3) no significant expression of Fos protein in either the basolateral or central

\section{Learning \& Memory \\ www.learnmem.org}


A)

\section{Granule Cell Layer - Olfactory Bulb}
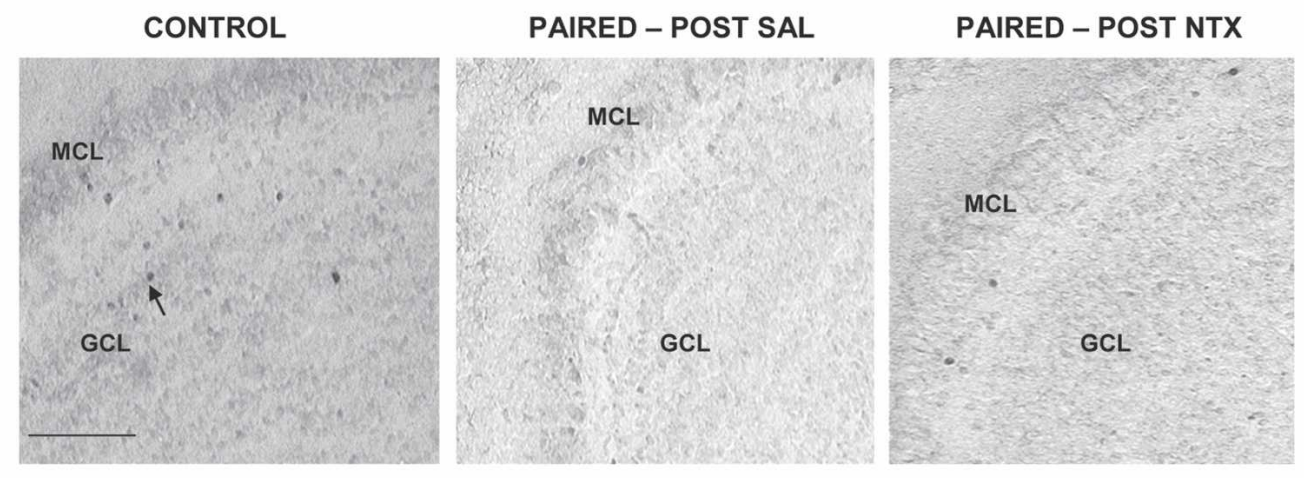

B)

Amygdala - Central Nucleus

PAIRED - POST SAL
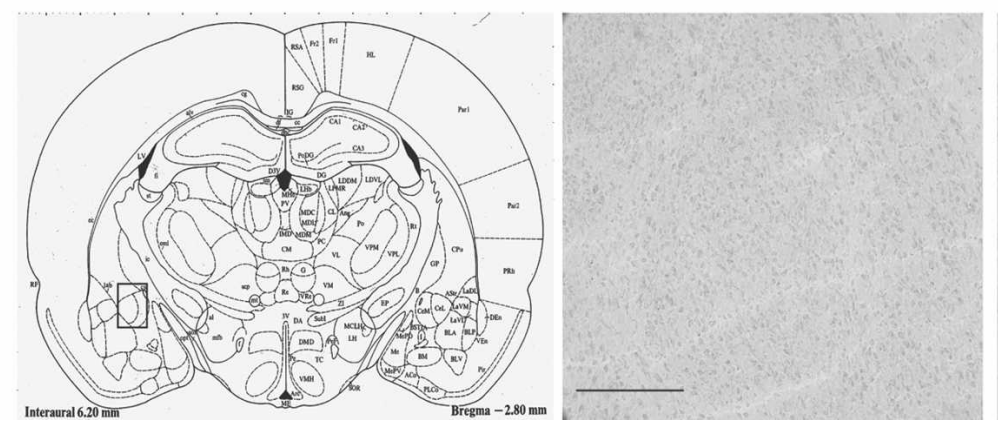

PAIRED - POST NTX

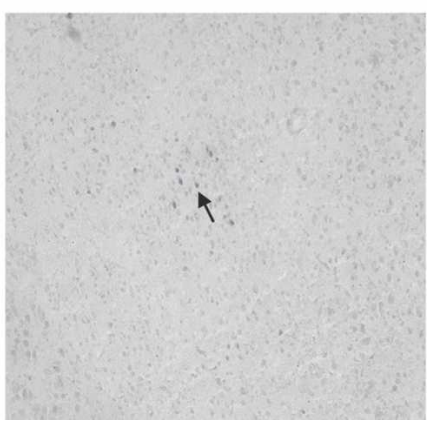

Figure 4. (A) Representative Fos protein expression in the olfactory bulb following control or experimental treatment. MCL indicates mitral cell layer; GCL, granule cell layer; SAL, saline; and NTX, naltrexone. Arrow designates an example of a Fos-positive cell. $10 \times$; horizontal scale bar, $100 \mu \mathrm{m}$. $(B)$ Representative Fos protein expression in the central nucleus of the amygdala. Schematic section reprinted with permission from Elsevier $\odot 1986$, Paxinos and Watson (1986). The square indicates the area shown in the two right panels $(10 \times)$.

amygdaloidal nuclei. Post-training treatment with NTX, which behaviorally switches memory consolidation from a preference to an aversion, changes this pattern of Fos protein expression, presumably contributing to the switch in memory. Specifically, in these neonates, NTX following paired presentations of odor and shock produced in concert: (1) a significant decrease in Fos protein expression in the granule cell layer of the olfactory bulb,

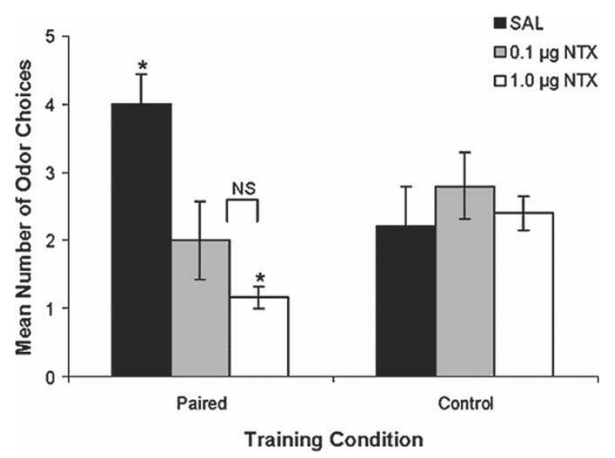

Figure 5. Infusion of NTX into the neonate amygdala following odorshock conditioning yields consolidation of an odor aversion instead of a preference. Bars represent the number of choices (mean \pm SEM) toward peppermint during $\mathrm{Y}$-maze testing for pups that received paired presen-

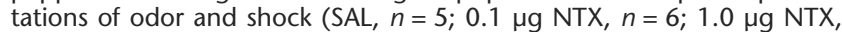
$n=6$ ) or control presentations (SAL, $n=5 ; 0.1 \mu \mathrm{g} \mathrm{NTX}, n=5 ; 1.0 \mu \mathrm{g}$ NTX, $n=5$ ). SAL indicates saline; NTX, naltrexone. ${ }^{*} P<0.05$.
(2) no increase in Fos protein expression in the anterior piriform cortex, and (3) significant Fos protein expression in the central nucleus of the amygdala. And finally, we now document that intra-amygdala infusion of NTX following training prevents consolidation of the conditioned odor preference and instead yields an odor aversion. Overall, cellular and behavioral results demonstrate the prominent role of opioid modulation of neonate memory.

\section{Olfactory bulb}

Physiological and cellular changes within the olfactory bulb have been well-documented to support learned odor associations in rat pups (Wilson et al. 1987; Woo et al. 1996; Yuan et al. 2003; Zhang et al. 2003a,b). Odor learning and memory in rat pups evokes bulbar cAMP-PKA and MAPK/ERK cellular cascades (Yuan et al. 2003; Zhang et al. 2003a,b; Harley et al. 2006), which is the result of a large influx of norepinephrine (NE) released by the locus coeruleus (LC) (Sullivan et al. 1992, 2000b; Sullivan and Wilson 1994; Rangel and Leon 1995; Moriceau and Sullivan 2004b). And this large influx of NE prevents mitral cell (output neurons) habituation to repeated odor presentations (Sullivan and Wilson 1994, 2003; Okutani et al. 1998; Yuan et al. 2003). Granule cells (inhibitory interneurons) play a prominent role in learning and memory by modulating mitral cell activity (Wilson and Leon 1988; Trombley and Shepherd 1992), and less inhibition of the olfactory bulb via a decrease in granule cell activity has already been shown to be important in pup learning and 
A)

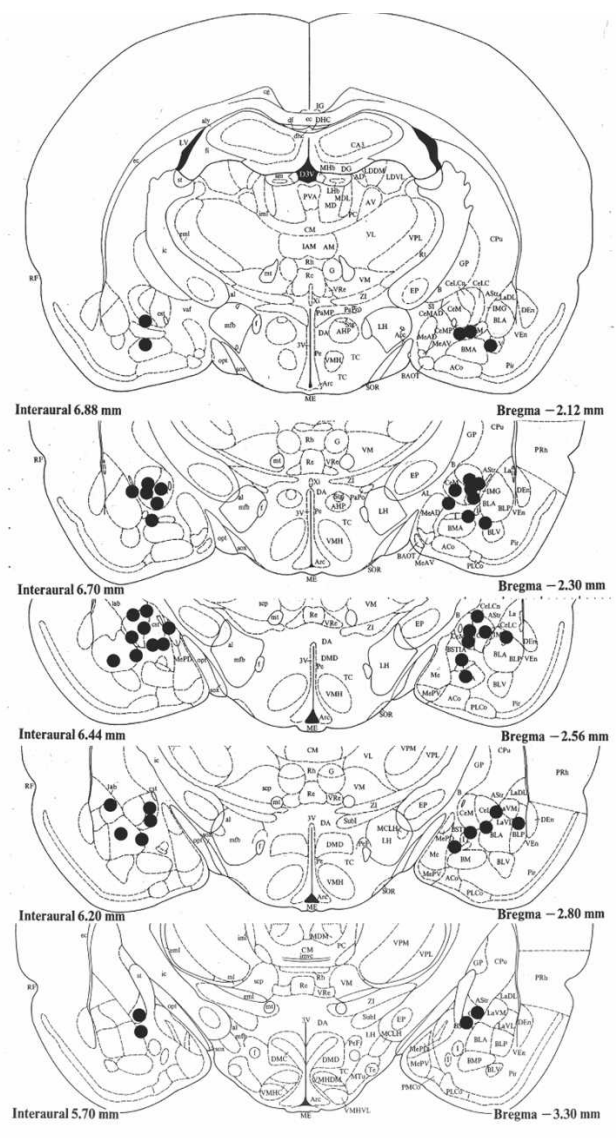

B)

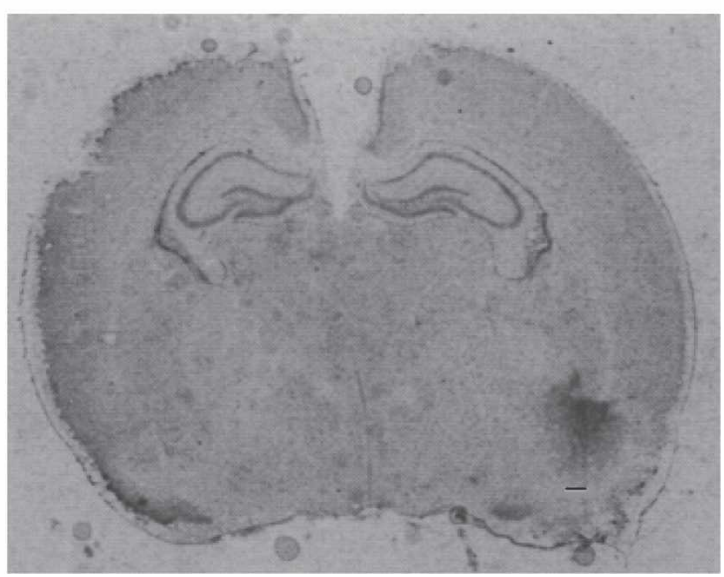

Figure 6. (A) Reconstruction of bilateral cannula tips (dots) within the amygdala in rat neonates in Experiment 2. Distance from bregma for each coronal section is noted to the right. Schematic sections reprinted with permission from Elsevier (c) 1986, Paxinos and Watson (1986). (B) Characterization of drug diffusion over the region of the amygdaloid complex. Overlay of $\left[{ }^{3} \mathrm{H}\right]$ Naloxone diffusion on a histological section counterstained with cresyl violet demonstrates drug diffusion over the region is $<1 \mathrm{~mm}$. Horizontal scale bar, $2 \mathrm{~mm}$.

memory (Sullivan and Wilson 1994, 2003; Woo et al. 1996). Our current results show that paired presentations of odor and shock resulted in less Fos-positive cells in the granule cell layer, further supporting the observation that a decrease in granule cell activity supports learning and memory.

\section{Piriform cortex}

Mitral cell axons directly project to the anterior piriform cortex (Schwob and Price 1984; Haberly 2001), and both the anterior and posterior piriform cortex contribute to adult sensory perception and learning, although the posterior piriform appears to have a greater role in adult learning and memory (Litaudon et al. 1997; Barkai and Saar 2001; Datiche et al. 2001; Linster and Hasselmo 2001; Tronel and Sara 2002; Sevelinges et al. 2004; Wilson et al. 2004). Within the piriform, opioid receptors are colocalized with GABAergic neurons and thus directly modulate inhibitory activity and indirectly modulate excitatory activity (Kalyuzhny and Wessendorf 1998). Our results suggest that endogenous opioid modulation of piriform cortical activity (directly or indirectly) plays an important role in learned hedonic value. Specifically, an odor preference appears attributable to learninginduced activity in the anterior piriform, while an odor aversion appears attributable to no appreciable activity in the anterior piriform cortex.

\section{Amygdala}

Olfactory information reaches the amygdala through direct mitral cell input to the cortical amygdala (Price 1973) as well as through indirect input from the posterior piriform cortex (Schwob and Price 1984; Haberly 2001), although it is unclear how effective these connections are during the first post-natal week. The basolateral/lateral amygdala receives input from multiple sensory systems and is thus considered to have a critical role in fear conditioning through stimuli convergence (LeDoux et al. 1990; Pitkanen et al. 2003). Controlling conditioned behavioral responses, the central nucleus of the amygdala receives the integrated information and serves as an interface for motor output (LeDoux and Muller 1997; Fendt and Fanselow 1999).

Within both the basolateral and central amygdala, opioids modulate noradrenergic activity (Introini-Collison et al. 1989; Watanabe et al. 2003). The NTX-induced amygdala activity offers another plausible explanation for the odor aversion, since neonate learning does not evoke significant amygdala activity under normal conditions (Sullivan and Wilson 1993; Sullivan et al. 2000a; Moriceau et al. 2006), presumably underlying an attenuated ability to learn odor-shock aversions. Learned aversions are intimately associated with amygdala activity in older pups and adults (Sullivan et al. 2000a; Packard and Cahill 2001; Schafe et al. 2001; Walker and Davis 2002; Fanselow and Gale 2003; Maren 2003; McIntyre et al. 2003; Moriceau et al. 2006), mediated through NE input (McGaugh et al. 1988; Liang et al. 1990; McIntyre et al. 2003). Indeed, opioid receptor antagonism in the adult amygdala potentiates noradrenergic input (Quirate et al. 1998), thus facilitating learned inhibitory responses. We failed to detect NTX-induced changes in Fos expression in the basolateral/lateral amygdala; however, this may reflect the sensitivity of Fos expression to the time interval between training and brain removal. Thus, we cannot rule out effects of post-training opioid receptor antagonism on the basolateral/lateral amygdala.

However, we did see changes within the central amygdala. The significant Fos activity in the central amygdala suggests that NTX removed inhibitory control (directly or indirectly) of the neonate amygdala, which was specific to temporal presentations of the stimuli since there were no changes in the unpaired training condition. Indeed, opioid agonists have been shown to inhibit neurons within the adult central amygdala (Freedman and Aghajanian 1985; Zhu and Pan 2004). Behavior results from Experiment 2 demonstrate that post-training disruption of opioid activity within the amygdala not only is sufficient to disrupt consolidation of the odor preference but permits consolidation of an aversion. Overall, our results suggest that opioid modula-

\section{Learning \& Memory}

www.learnmem.org 
tion of the neonate amygdala during memory consolidation plays a pivotal role in unique behavior displayed during the first post-natal week (learned odor preferences despite an aversive conditioning paradigm).

\section{Conclusions}

In conclusion, our results demonstrate that opioid modulation of patterns of a synaptic plasticity gene product in neonate odor learning and memory circuitry, specifically in the piriform cortex and amygdala, underlies the memory of conditioned odor preferences and avoidances. This suggests that opioids have a pivotal role in modulation of fear circuitry in neonates, ultimately supporting the unique learning and memory characteristics necessary for infant attachment to the caretaker-enhanced preference learning and memory and attenuated fear.

\section{Materials and Methods}

\section{Subjects}

We used male and female pups born of Long-Evans rats (Harlan, IN) in the animal vivarium. Mothers were housed in polypropylene cages with aspen wood shavings and kept in a $20^{\circ} \mathrm{C}$ environment with a 12-h light/12-h dark cycle. Food and water were available ad libitum. Litters were culled to 10-12 males and females on PN1 or 2, with PNO designated as the day of birth. The University of Oklahoma Institutional Animal Care and Use Committee, which follows guidelines from the National Institutes of Health, approved all animal care and experimental procedures. Subject numbers for experiments are listed in the corresponding figure legends.

\section{Experiment 1}

\section{Training and testing}

PN7-8 pups were randomly assigned to one of the following training conditions: (1) paired odor-shock, (2) unpaired odorshock, and (3) odor-only presentations. Pups were removed from the nest and given a 10-min recovery period following placement inside individual $600-\mathrm{mL}$ beakers that were maintained at $30 \pm 0.1^{\circ} \mathrm{C}$ (ambient temperature was also maintained at $30 \pm 0.1^{\circ} \mathrm{C}$ ). During the training session, pups received 14 presentations of a 30-sec peppermint odor (CS; McCormick Pure Peppermint) and a 1-sec $0.5 \mathrm{~mA}$ tail-shock (US; Lafayette Instruments), with an intertrial interval of 4 min. Paired odor-shock subjects received 14 pairings of the 30 -sec odor with shock during the last second of the odor presentation, while unpaired odorshock subjects received a 1 -sec shock $\sim 2$ min following the odor presentation. Odor-only subjects received just the odor presentations. As pups were not restrained within the beaker, shock was manually delivered by application of an electrode to the base of the tail. It should be noted that the shock-induced odor preference can also be induced using tail shock with an electrode adhered to the tail or with foot-shock delivered through a floor grid (Sullivan et al. 2000a).

A flow-dilution olfactometer was created by using flow meters (Laboratory Supplies Co. Inc.) to deliver the odor at a flow rate of $2 \mathrm{~L} / \mathrm{min}$ and at a concentration of 1 peppermint vapor: 10 clean air. To ensure the peppermint odor was adequately removed between odor presentations, training occurred in front of a ventilation hood, which provided a continuous flow of air within the training beaker. This odor delivery system produces responses from the olfactory bulb's primary output neurons (Wilson and Sullivan 1992) and produces robust odor conditioning (Sullivan et al. 2000a; Roth and Sullivan 2001, 2003, 2005; Ressler et al. 2002; Sevelinges et al. 2004). Immediately following training, pups received systemic injections of $0.5 \mathrm{mg} / \mathrm{kg}$ naltrexone hydrochloride (NTX; Sigma Chemical) or isotonic saline in the nape of the neck. Pups used for behavior were placed in a $30^{\circ} \mathrm{C}$ incubator for $15 \mathrm{~min}$ and then returned to the nest until testing. Pups used for Fos analysis were placed in a $30^{\circ} \mathrm{C}$ incubator, and their brains removed as described below.

Pups were tested the following day (in the absence of any drugs) in a Y-maze, which consisted of a $7 \mathrm{~cm}$ (length) $\times 9 \mathrm{~cm}$ (width) habituation chamber, and two $22 \mathrm{~cm}$ (length) $\times 9 \mathrm{~cm}$ (width) alleys. At the end of one arm of the maze was the peppermint odor $(25 \mu \mathrm{L}$ of peppermint extract on a Kim wipe that had been placed in a ventilation hood for $5 \mathrm{~min}$ ), and at the end of the other arm was the odor of clean aspen wood shavings (20 $\mathrm{mL}$ of clean shavings in a Petri dish). A pup was placed in the startbox for $5 \mathrm{sec}$ and then given $60 \mathrm{sec}$ to make a choice. Once a pup made a selection, by entering at the minimum $3 \mathrm{~cm}$ into either the peppermint arm or clean shavings arm (but it should be noted that the majority of pups walk down the entire length of an arm to approach the odor), it was removed immediately. Pups were given five sequential trials with a 30 -sec intertrial interval. The start direction of the pup was counterbalanced between trials to eliminate any turning biases. Distilled water was used to clean the maze floor between testing trials. Behavioral testing was performed without knowledge of training condition. The number of choices toward peppermint odor was determined across training and drug conditions with both ANOVA and posthoc Fisher tests. To simplify analysis and presentation, the unpaired and odor-only control conditions were collapsed after no differences were observed between the groups.

In pups used for analysis of Fos protein expression (thus not tested in a Y-maze), we assessed pups' learning during odorshock training using a rating scale that accommodates pups' motoric immaturity $(0$, no movement; 5 , movement of all limbs and head) to assess conditioned behavioral activation $10 \mathrm{sec}$ prior to each odor presentation and during each odor presentation (Hall 1979; Landers and Sullivan 1999; Roth and Sullivan 2001, 2003, 2005). The maximum amount of movement during each observation period was recorded, excluding the response to shock. To simplify data analysis, ratings from two consecutive trials were summed; thus the maximum conditioned behavioral response a subject could show would be 10 . Behavioral acquisition was determined across training and drug conditions using repeatedmeasures ANOVA and post hoc Fisher tests. The unpaired and odor-only conditions were collapsed for analysis and presentation after no differences were observed between the two conditions. It should be noted that while pups appear to follow many of the adult rules associated with classical conditioning (for a review, see Sullivan 2001; Roth et al. 2004), learning has never been documented in pups receiving unpaired presentations of odor and a reward (Spear 1978; Spear and Rudy 1991; Dominguez et al. 1999; Sullivan et al. 2000a; Roth and Sullivan 2001, 2003, 2005; Moriceau and Sullivan 2004b; Moriceau et al. 2004).

\section{c-fos immunohistochemistry}

Ninety minutes following training and drug treatment, brains were removed and frozen in 2-methylbutane $\left(-45^{\circ} \mathrm{C}\right)$ and placed in a $-70^{\circ} \mathrm{C}$ freezer until cutting and post-fixation. Every sixth section (coronal sections, $20 \mu \mathrm{m}$ ) was collected on pretreated slides (Fisherbrand Plus, Fisher) for Fos processing, and every seventh section was collected for cresyl violet staining. Fos sections received a 1 -h post-fix in $4 \%$ paraformaldehyde/0.1 $\mathrm{M}$ phosphate buffer ( $\mathrm{PB}, \mathrm{pH}$ 7.2). To eliminate peroxidase activity, sections were incubated in $0.1 \mathrm{M} \mathrm{PB}$ saline (PBS; pH 7.2) containing 3\% $\mathrm{H}_{2} \mathrm{O}_{2}$ and $10 \%$ methanol for $5 \mathrm{~min}$. Following PBS rinses and 15 -min incubation in $0.2 \%$ Triton $\mathrm{X}-100$, slides were incubated in $3 \%$ bovine serum albumin for $1 \mathrm{~h}$. Slides were treated overnight at $4^{\circ} \mathrm{C}$ with the primary antibody (c-fos, sc-52, Santa Cruz Biotechnology) diluted 1:500 in PBS. Afterward, they were incubated in the secondary biotinylated antibody (goat anti-rabbit, Vector Laboratories) for $2 \mathrm{~h}$ at room temperature and then were incubated for $90 \mathrm{~min}$ in avidin-biotin-peroxidase (ABC) complex solution. Slides were then treated with $\mathrm{PB}$ containing $0.1 \% 3,3^{\prime}$ diaminobenzidine and $\mathrm{H}_{2} \mathrm{O}_{2}$ and subsequently dehydrated in alcohol and Histoclear, and coverslipped for microscope examination (Moriceau et al. 2004; Roth and Sullivan 2005).

Fos-positive cells were counted bilaterally using a microscope (Olympus with $10 \times$ objective) equipped with a drawing 
tube. With aid of a stereotaxic atlas (Paxinos and Watson 1986), brain areas were outlined using the corresponding cresyl violet sections. All Fos-positive cells were counted without knowledge of the training condition. Fos-positive cells were distinguished from the background by density of staining, shape, and size of cells. The mean number of Fos cells per brain area for an animal was determined by averaging the counts from all sections (two sections counted for each brain area). Brain areas examined were the granule cell layer of the olfactory bulb, the anterior and posterior piriform cortex, and the basolateral/lateral and central nuclei of the amygdaloid complex. The number of Fos-positive cells within each brain region was determined across training and drug conditions using ANOVA and post hoc Fisher tests. To simplify the analysis and graphical representation, the unpaired and odor-only control conditions were collapsed after no differences were observed between the training conditions. Again, while unpaired presentations of a conditioned stimulus and unconditioned stimulus may produce learning in adults, this is not the case in infant rats (Rescorla 1967; Spear 1978; Spear and Rudy 1991; Dominguez et al. 1999; Sullivan et al. 2000a; Roth and Sullivan 2001, 2003, 2005; Moriceau and Sullivan 2004b; Moriceau et al. 2004). Furthermore, we have previously presented data that there are no differences in Fos expression between the unpaired odor-shock and odor-only control conditions (Roth and Sullivan 2005), which is also consistent with neural analysis of these two conditions using a radioactive label (Sullivan et al. 2000a).

\section{Experiment 2}

\section{Surgery}

On PN5-6, pups were anesthetized with Isoflurane (until elimination of tailpinch reflex) and placed in a stereotaxic apparatus with bregma and $\lambda$ coordinates in the same horizontal plane. Stainless steel cannulas (30-gauge tubing) were implanted bilaterally in the amygdaloid complex $(-0.8 \mathrm{~mm}$ posterior, $\pm 3.0 \mathrm{~mm}$ lateral, and $5.0 \mathrm{~mm}$ ventral to bregma) via holes drilled through the skull. Cannulas were attached to the skull with dental acrylic. In addition, clear nail polish (Onyx Laboratories), which has a foul taste, was painted around sutures to prevent removal by the mother. Pups were given $\sim \mathrm{h}$ for recovery in a $30^{\circ} \mathrm{C}$ incubator before return to the home cage.

\section{Training and testing}

On PN7-8, pups were placed in individual glass beakers, with their cannulas connected by PE10 tubing to Harvard syringe pumps controlling Hamilton $10-\mu \mathrm{L}$ syringes. Pups were odorshock conditioned as described in Experiment 1. Immediately following conditioning, the cannulas were filled (volume of $1 \mu \mathrm{L}$ ) with isotonic saline, 0.1 , or $1.0 \mu \mathrm{g}$ NTX dissolved in saline, at a rate of $1.0 \mu \mathrm{L} / \mathrm{min}$ for $1 \mathrm{~min}$. In previous studies from our laboratory and others, similar infusion volumes and rates have been used to selectively deliver drugs to various regions of the neonate brain (Sullivan et al. 1992, 2000b; Moriceau and Sullivan 2004b).

Following training/drug infusion, pups were given a $15-\mathrm{min}$ recovery period in an incubator and returned to the home cage until testing. The following day, pups were tested in a behavioral Y-maze (in the absence of any drugs) as described in Experiment 1. Following testing, brains were removed and stained with cresyl violet to verify cannula placement within the amygdala complex. The number of choices toward peppermint odor was determined across training and drug conditions with both ANOVA and post hoc Fisher tests. To simply analysis and presentation, the unpaired and odor-only control conditions were collapsed after no differences were observed between the groups.

\section{Drug diffusion}

To characterize the extent of drug diffusion within and outside of the amygdaloid complex, additional pups were used. On PN6, pups were anesthetized by urethane and placed in a stereotaxic apparatus. Holes were drilled through the skull at $0.8 \mathrm{~mm}$ posterior to bregma, and $\pm 3.0 \mathrm{~mm}$ from the midline. A $10-\mu \mathrm{L}$
Hamilton syringe was slowly lowered $5.0 \mathrm{~mm}$ from the surface of the skull, placing the tip within the amygdaloid complex. Pups were infused (unilaterally) for 1 min with $1 \mu \mathrm{L}$ of a saline solution of $\left[{ }^{3} \mathrm{H}\right]$ Naloxone $(1 \mu \mathrm{Ci} / \mu \mathrm{L}$; Amersham Biosciences Products). We chose to use $\left[{ }^{3} \mathrm{H}\right]$ Naloxone as it is another nonspecific opioid receptor antagonist that is commercially available $\left(\left[{ }^{3} \mathrm{H}\right]\right.$ Naltrexone is not commercially available). After the infusion, the brains were quickly removed and frozen in 2 -methylbutane at $-45^{\circ} \mathrm{C}$ and sliced in $20-\mu \mathrm{m}$ coronal sections. The slides were apposed to a tritium storage phosphor screen (Amersham Biosciences). After $14 \mathrm{~d}$ of exposure, the screen was scanned at a pixel density of 50 $\mu \mathrm{m}$ (5000 dots per $\mathrm{cm}^{2}$ ) with a STORM 820 Phosphor Imager (Molecular Dynamics). Phosphorimaging of the slides results in a TIFF image file (Tucker et al. 2002; Moriceau and Sullivan 2004b).

\section{Acknowledgments}

We thank Gordon A. Barr, Joseph A. Bastian, Douglas D. Gaffin, Eric D. Roth, and Donald A. Wilson for comments on the manuscript. We also thank Ashley Hollingsworth and Cathrine Miner for experimental assistance. This work was funded by grants HHS-PHS NRSA F31 DA06082 to T.L.R. and NICHD-HD33402 and NSF-IBN0117234 to R.M.S.

\section{References}

Atweh, S.F. and Kuhar, M.J. 1977. Autoradiographic localization of opiate receptors in rat brain, III: The telencephalon. Brain Res. 134: $393-405$.

Barkai, E. and Saar, D. 2001. Cellular correlates of olfactory learning in the rat piriform cortex. Rev. Neurosci. 12: 111-120.

Barr, G.A. and Rossi, G. 1992. Conditioned place preference from ventral tegmental injection of morphine in neonatal rats. Brain Res. Dev. Brain Res. 66: 133-136.

Camp, L.L. and Rudy, J.W. 1988. Changes in the categorization of appetitive and aversive events during postnatal development of the rat. Dev. Psychobiol. 21: 25-42.

Datiche, F., Roullet, F., and Cattarelli, M. 2001. Expression of Fos in the piriform cortex after acquisition of olfactory learning: An immunohistochemical study in the rat. Brain Res. Bull. 55: 95-99.

Davis, M., Walker, D.L., and Myers, K.M. 2003. Role of the amygdala in fear extinction measured with potentiated startle. Ann. N.Y. Acad. Sci. 985: 218-232.

Dominguez, H.D., Lopez, M.F., and Molina, J.C. 1999. Interactions between perinatal and neonatal associative learning defined by contiguous olfactory and tactile stimulation. Neurobiol. Learn. Mem. 71: $272-288$.

Dragunow, M. and Bilkey, D. 2002. Neuroanatomical and functional mapping using activation of transcription factors. In Handbook of chemical neuroanatomy: Immediate early genes and inducible transcription factors in mapping of the central nervous system function and dysfunction, Vol. 19 (eds. L. Kaczmarek and H.A. Robertson), pp. 39-44. Elsevier, New York.

Fanselow, M.S. 1984. Opiate modulation of the active and inactive components of the postshock reaction: Parallels between naloxone pretreatment and shock intensity. Behav. Neurosci. 98: 269-277.

Fanselow, M.S. and Gale, G.D. 2003. The amygdala, fear, and memory. Ann. N. Y. Acad. Sci. 985: 125-134.

Fanselow, M.S. and Poulos, A.M. 2005. The neuroscience of mammalian associative learning. Annu. Rev. Psychol. 56: 207-234.

Fanselow, M.S., Kim, J.J., Young, S.L., Calcagnetti, D.J., DeCola, J.P., Helmstetter, F.J., and Landeira-Fernandez, J. 1991. Differential effects of selective opioid peptide antagonists on the acquisition of Pavlovian fear conditioning. Peptides 12: 1033-1037.

Fendt, M. and Fanselow, M.S. 1999. The neuroanatomical and neurochemical basis of conditioned fear. Neurosci. Biobehav. Res. 23: $743-760$.

Freedman, J.E. and Aghajanian, G.K. 1985. Opiate and $\alpha_{2}$-adrenoceptor responses of rat amygdaloid neurons: Co-localization and interactions during withdrawal. J. Neurosci. 5: 3016-3024.

Good, A.J. and Westbrook, R.F. 1995. Effects of microinjections of morphine into the amygdala on the acquisition and expression of conditioned fear and hypoalgesia in rats. Behav. Neurosci. 109: 631-641.

Haberly, L.B. 2001. Parallel-distributed processing in olfactory cortex New insights from morphological and physiological analysis of neuronal circuitry. Chem. Senses 26: 551-576.

Hall, W.G. 1979. The ontogeny of feeding in rats, I: Ingestive and behavioral responses to oral infusions. J. Comp. Physiol. Psychol. 93: $977-1000$. 
Harley, C.W., Darby-King, A., McCann, J., and McLean, J.H. 2006 $\beta_{1}$-Adrenoceptor or $\alpha_{1}$-adrenoceptor activation initiates early odor preference learning in rat pups: Support for the mitral cell/cAMP model of odor preference learning. Learn. Mem. 13: 8-13.

Harlow, H.F. and Harlow, M.K. 1965. The affectional systems. In Behavior of nonhuman primates, Vol. 2 (eds. A. Schrier et al.), pp. 287-334. Academic Press, New York.

Herrera, D.G. and Robertson, H.A. 1996. Activation of c-fos in the brain. Prog. Neurobiol. 50: $83-107$.

Hess, E.H. 1962. Ethology: An approach to the complete analysis of behavior. In New directions in psychology (eds. R. Brown et al.), pp. 159-199. Rinehart and Winston, New York.

Introini-Collison, I.B., Nagahara, A.H., and McGaugh, J.L. 1989 Memory enhancement with intra-amygdala post-training naloxone is blocked by concurrent administration of propanolol. Brain Res. 476: $94-101$

Kaczmarek, L. 2002. c-Fos in learning: Beyond the mapping of neuronal activity. In Handbook of chemical neuroanatomy: Immediate early genes and inducible transcription factors in mapping of the central nervous system function and dysfunction, Vol. 19 (eds. L. Kaczmarek and H.A. Robertson), pp. 189-215. Elsevier, New York.

Kalyuzhny, A.E. and Wessendorf, M.W. 1998. Relationship of $\mu$ and $\delta$ opioid receptors to GABAergic neurons in the central nervous system, including antinociceptive brainstem circuits. J. Comp. Neurol. 392: 528-547.

Kehoe, P. and Blass, E.M. 1986. Behaviorally functional opioid system in infant rats I: Evidence for olfactory and gustatory classical conditioning. Behav. Neurosci. 100: 359-367.

Lalumiere, R.T., Nguyen, L.T., and McGaugh, J.L. 2004. Post-training intrabasolateral amygdala infusions of dopamine modulate consolidation of inhibitory avoidance memory: Involvement of noradrenergic and cholinergic systems. Eur. J. Neurosci. 20: $2804-2810$.

Landers, M.S. and Sullivan, R.M. 1999. Norepinephrine and associative conditioning in the neonatal rat somatosensory system. Brain Res. Dev. Brain Res. 114: 261-264.

LeDoux, J.E. and Muller, J. 1997. Emotional memory and psychopathology. Philos. Trans. R. Soc. Lond. B Biol. Sci. 352: 1719-1726.

LeDoux, J.E., Cicchetti, P., Xagoraris, A., and Romanski, L.M. 1990. The lateral amygdaloid nucleus: Sensory interface of the amygdala in fear conditioning. J. Neurosci. 10: 1062-1069.

Liang, K.C., McGaugh, J.L., and Yao, H. 1990. Involvement of amygdala pathways in the influence of posttraining amygdala norepinephrine and peripheral epinephrine on memory storage. Brain Res. 508: $225-233$.

Linster, C. and Hasselmo, M.E. 2001. Neuromodulation and the functional dynamics of piriform cortex. Chem. Senses 26: 585-594.

Litaudon, P., Mouly, A., Sullivan, R., Gervais, R., and Cattarelli, M. 1997. Learning-induced changes in rat piriform cortex activity mapped using multisite recording with voltage sensitive dye. Eur. J. Neurosci. 9: 1593-1602.

Maestripieri, D., Wallen, K., and Carroll, K.A. 1997. Infant abuse runs in families of group-living pigtail macaques. Child Abuse Negl. 21: $465-471$.

Maestripieri, D., Tomaszycki, M., and Carroll, K.A. 1999. Consistency and change in the behavior of rhesus macaque abusive mothers with successive infants. Dev. Psychobiol. 34: 29-35.

Mansour, A., Khachaturian, H., Lewis, M.E., Akil, H., and Watson, S.J. 1987. Autoradiographic differentiation of $\mu, \delta$, and $\kappa$ opioid receptors in the rat forebrain and midbrain. J. Neurosci. 7: $2445-2464$

Maren, S. 2001. Neurobiology of Pavlovian fear conditioning. Annu. Rev. Neurosci. 24: 897-931.

. 2003. The amygdala, synaptic plasticity, and fear memory. Ann. N.Y. Acad. Sci. 985: 106-113.

McGaugh, J.L. 2004. The amygdala modulates the consolidation of memories of emotionally arousing experiences. Annu. Rev. Neurosci. 27: $1-28$.

McGaugh, J.L., Introini-Collison, I.B., and Nagahara, A.H. 1988. Memory-enhancing effects of posttraining naloxone: Involvement of $\beta$-noradrenergic influences in the amygdaloid complex. Brain Res. 446: $37-49$.

McIntyre, C.K., Power, A.E., Roozendaal, B., and McGaugh, J.L. 2003. Role of the basolateral amygdala in memory consolidation. Ann. N.Y. Acad. Sci. 985: 273-293.

McNally, G.P., Pigg, M., and Weidemann, G. 2004. Blocking, unblocking, and overexpectation of fear: A role of opioid receptors in regulation of pavlovian association formation. Behav. Neurosci. 118: $111-120$.

Moles, A., Kieffer, B.L., and D'Amota, F.R. 2004. Deficit in attachment behavior in mice lacking the $\mu$-opioid receptor gene. Science
304: 1983-1986.

Moriceau, S. and Sullivan, R.M. 2004a. Corticosterone influences on mammalian neonatal sensitive-period learning. Behav. Neurosci. 118: $274-281$.

2004b. Unique neural circuitry for neonatal olfactory learning. J. Neurosci. 24: 1182-1189.

Moriceau, S., Roth, T.L., Okotoghaide, T., and Sullivan, R.M. 2004. Corticosterone controls the developmental emergence of fear and amygdala function to predator odors in infant rat pups. Int. J. Dev. Neurosci. 22: 415-422.

Moriceau, S., Wilson, D.A., Levine, S., and Sullivan, R.M. 2006. Dual circuitry for odor-shock conditioning during infancy: Corticosterone switches between fear and attraction via amygdala. J. Neurosci. 26: 6737-6748.

Okutani, F., Kaba, H., Takahashi, S., and Seto, K. 1998. The biphasic effects of locus coeruleus noradrenergic activation on dendrodendritic inhibition in the rat olfactory bulb. Brain Res. 783: $272-279$

Packard, M.G. and Cahill, L. 2001. Affective modulation of multiple memory systems. Curr. Opin. Neurobiol. 11: 752-756.

Panksepp, J., Nelson, E., and Siviy, S. 1994. Brain opioids and mother-infant social motivation. Acta. An. Pediatr. (Barc.) Suppl. 397: 40-46.

Paxinos, G. and Watson, C. 1986. The rat brain in stereotaxic coordinates. Academic Press, San Diego, CA.

Pezze, M.A. and Feldon, J. 2004. Mesolimbic dopaminergic pathways in fear conditioning. Prog. Neurobiol. 74: 301-320.

Pitkanen, A., Savander, M., Nurminen, N., and Ylinen, A. 2003. Intrinsic synaptic circuitry of the amygdala. Ann. N.Y. Acad. Sci. 985: 34-49.

Price, J.L. 1973. An autoradiographic study of complementary laminar patterns of termination of afferent fibers to the olfactory cortex. $J$. Comp. Neurol. 150: $87-108$.

Quirate, G.L., Galvez, R., Roozendaal, B., and McGaugh, J.L. 1998. Norepinephrine release in the amygdala in response to footshock and opioid peptidergic drugs. Brain Res. 808: 134-140.

Rajecki, D.W., Lamb, M.E., and Obmascher, P. 1978. Toward a general theory of infantile attachment: A comparative review of aspects of the social bond. Behav. Brain Sci. 3: 417-464.

Randall, C.K., Kraemer, P.J., Dose, J.M., Carbary, T.J., and Bardo, M.T. 1992. The biphasic effect of morphine on odor conditioning in neonatal rats. Dev. Psychobiol. 25: 355-364.

Rangel, S. and Leon, M. 1995. Early odor preference training increases olfactory bulb norepinephrine. Brain Res. Dev. Brain Res. 85: $187-191$.

Rescorla, R.A. 1967. Pavlovian conditioning and its proper control procedures. Psychol. Rev. 74: 71-80.

Ressler, K.J., Paschall, G., Zhou, X., and Davis, M. 2002. Regulation of synaptic plasticity genes during consolidation of fear conditioning. $J$. Neurosci. 22: 7892-7902.

Roth, T.L. and Sullivan, R.M. 2001. Endogenous opioids and their role in odor preference acquisition and consolidation following odor-shock conditioning in infant rats. Dev. Psychobiol. 39: 188-198.

- 2003. Consolidation and expression of a shock-induced odor preference in rat pups is facilitated by opioids. Physiol. Behav. 78: $135-142$.

- 2005. Memory of early maltreatment: Neonatal behavioral and neural correlates of maternal maltreatment within the context of classical conditioning. Biol. Psychiatry 57: 823-831.

Roth, T.L., Wilson, D.A., and Sullivan, R.M. 2004. Neurobehavioral development of infant learning and memory: Implications for infant attachment. In Advances in the study of behavior, Vol. 34 (eds. P.J.B. Slater et al.), pp. 103-133. Academic Press, San Diego.

Rudy, J.W. and Matus-Amat, P. 2005. The ventral hippocampus supports a memory representation of context and contextual fear conditioning: Implications for a unitary function of the hippocampus. Behav. Neurosci. 119: 154-163.

Schafe, G.E., Atkins, C.M., Swank, M.W., Bauer, E.P., Sweatt, J.D., and LeDoux, J.E. 2000. Activation of ERK/MAP kinase in the amygdala is required for memory consolidation of pavlovian fear conditioning. $J$. Neurosci. 20: 8177-8187.

Schafe, G.E., Nader, K., Blair, H.T., and LeDoux, J.E. 2001. Memory consolidation of Pavlovian fear conditioning: A cellular and molecular perspective. Trends Neurosci. 24: 540-546.

Schwob, J.E. and Price, J.L. 1984. The development of axonal connections in the central olfactory system of rats. J. Comp. Neurol. 223: $177-202$.

Sevelinges, Y., Gervais, R., Messaoudi, B., Granjon, L., and Mouly, A.M 2004. Olfactory fear conditioning induces field potential potentiation in rat olfactory cortex and amygdala. Learn. Mem. 11: 761-769.

Shide, D.J. and Blass, E.M. 1991. Opioid mediation of odor preferences induced by sugar and fat in 6-day-old rats. Physiol. Behav. 


\section{Roth et al.}

50: $961-966$

Spear, N.E. 1978. Processing memories: forgetting and retention. Erlbaum, Hillsdale, NJ.

Spear, N.E. and Rudy, J.W. 1991. Tests of the ontogeny of learning and memory: Issues, methods, and results. In Developmental psychobiology: New methods and changing concepts (eds. H.N. Shair et al.), pp. 84-113. Oxford, New York.

Sullivan, R.M. 2001. Unique characteristics of neonatal classical conditioning: The role of the amygdala and locus coeruleus. Int Physiol. Behav. Sci. 36: 293-307.

Sullivan, R.M. and Wilson, D.A. 1993. Role of the amygdala complex in early olfactory associative learning. Behav. Neurosci. 107: 254-263. . 1994. The locus coeruleus, norepinephrine, and memory in newborns. Brain Res. Bull. 35: 467-472.

. 2003. Molecular biology of early olfactory memory. Learn. Mem. 10: $1-4$.

Sullivan, R.M., Zyzak, D.R., Skierkowski, P., and Wilson, D.A. 1992. The role of olfactory bulb norepinephrine in early olfactory learning. Brain Res. Dev. Brain Res. 70: 279-282.

Sullivan, R.M., Landers, M., Yeaman, B., and Wilson, D.A. 2000a. Good memories of bad events in infancy. Nature 407: 38-39.

Sullivan, R.M., Stackenwalt, G., Nasr, F., Lemon, C., and Wilson, D.A $2000 \mathrm{~b}$. Association of an odor with activation of olfactory bulb noradrenergic $\beta$-receptors or locus coeruleus stimulation is sufficient to produce learned approach responses to that odor in neonatal rats. Behav. Neurosci. 114: 957-962.

Trombley, P.Q. and Shepherd, G. 1992. Noradrenergic inhibition of synaptic transmission between mitral and granule cells in mammalian olfactory bulb cultures. J. Neurosci. 12: 3985-3991.

Tronel, S. and Sara, S.J. 2002. Mapping of olfactory memory circuits: Region specific c-fos activation after odor-reward associative learning or after its retrieval. Learn. Mem. 9: 105-111.

Tucker, D.L., Tucker, N., and Conway, T. 2002. Gene expression profiling of the $\mathrm{pH}$ response in Escherichia coli. J. Bacteriol. 183: 6551-6558.

Unterwald, E.M., Anton, B., To, T., Lam, H., and Evans, C.J. 1998. Quantitative immunolocalization of $\mu$ opioid receptors: Regulation by naltrexone. Neuroscience 85: 897-905.

Walker, D.L. and Davis, M. 2002. The role of amygdala glutamate receptors in fear learning, fear-potentiated startle, and extinction.
Pharmacol. Biochem. Behav. 71: 379-392.

Watanabe, T., Nakagawa, T., Yamamoto, R., Maeda, A., Minami, M., and Satoh, M. 2003. Involvement of noradrenergic system within the central nucleus of the amygdala in naloxone-precipitated morphine withdrawal-induced conditioned place aversion in rats. Psychopharmacology 170: 80-88.

Wilson, D.A. and Leon, M. 1988. Noradrenergic modulation of olfactory bulb excitability in the postnatal rat. Brain Res. Dev. Brain Res. 42: $69-75$.

Wilson, D.A. and Sullivan, R.M. 1992. Blockade of mitral-tufted cell habituation to odors by association with reward: A preliminary note. Brain Res. 594: 143-145.

Wilson, D.A., Sullivan, R.M., and Leon, M. 1987. Single-unit analysis of postnatal olfactory learning: Modified olfactory bulb output response patterns to learned attractive odors. J. Neurosci. 7: 3154-3162.

Wilson, D.A., Fletcher, M.L., and Sullivan, R.M. 2004. Acetylcholine and olfactory perceptual learning. Learn. Mem. 11: 28-34.

Woo, C.C., Oshita, M.H., and Leon, M. 1996. A learned odor response decreases the number of Fos-immunopositive granule cells in the olfactory bulb of young rats. Brain Res. 716: 149-156.

Yuan, Q., Harley, C.W., and McLean, J.H. 2003. Mitral cell $\beta 1$ and $5-\mathrm{HT}_{2 \mathrm{~A}}$ receptor colocalization and cAMP coregulation: A new model of norepinephrine-induced learning in the olfactory bulb. Learn. Mem. 10: 5-15.

Zhang, J.J., Okutani, F., Inoue, S., and Kaba, H. 2003a. Activation of the cyclic AMP response element-binding protein signaling pathway in the olfactory bulb is required for the acquisition of olfactory aversive learning in young rats. Neuroscience 117: 707-713.

. 2003b. Activation of the mitogen-activated protein kinase/extracellular signal-regulated kinase signaling pathway leading to cyclic AMP response element-binding protein phosphorylation is required for the long-term facilitation process of aversive olfactory learning in young rats. Neuroscience 121: 9-16.

Zhu, W. and Pan, Z.Z. 2004. Synaptic properties and postsynaptic opioid effects in rat central amygdala neurons. Neuroscience 127: 871-879.

Received April 28, 2006; accepted in revised form July 18, 2006. 


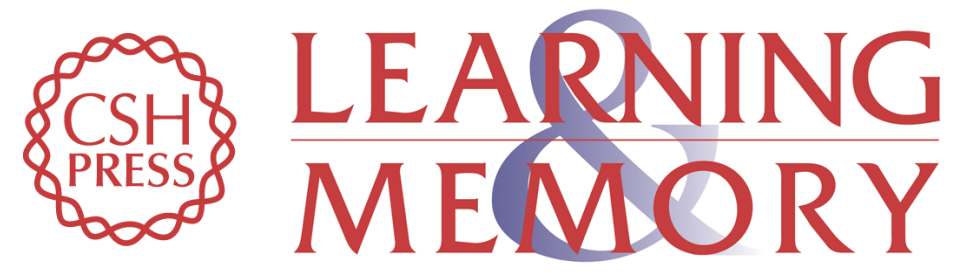

\section{Opioid modulation of Fos protein expression and olfactory circuitry plays a pivotal role in what neonates remember}

Tania L. Roth, Stephanie Moriceau and Regina M. Sullivan

Learn. Mem. 2006, 13:

Access the most recent version at doi:10.1101//m.301206

References This article cites 89 articles, 15 of which can be accessed free at: http://learnmem.cshlp.org/content/13/5/590.full.html\#ref-list-1

License

Email Alerting Receive free email alerts when new articles cite this article - sign up in the box at the Service top right corner of the article or click here. 